\title{
Use of oral glutamine in radiation-induced adverse effects in patients with thoracic and upper aerodigestive malignancies: Results of a prospective observational study
}

\author{
AMALIA PAPANIKOLOPOULOU ${ }^{1}$, NIKOLAOS SYRIGOS ${ }^{2}$, LOUISA VINI $^{3}$, MARIA PAPASAVVA ${ }^{4}$, \\ GEORGIOS LAZOPOULOS ${ }^{5}$, STELIOS KTENIADAKIS ${ }^{5}$, DEMETRIOS A. SPANDIDOS ${ }^{6}$, \\ ADRIANNI CHARPIDOU ${ }^{2}$ and NIKOLAOS DRAKOULIS ${ }^{4}$
}

\begin{abstract}
${ }^{1}$ Clinical Pharmacology Department, Athens Medical Center, 15125 Athens; ${ }^{2}$ Oncology Unit, 3rd Department of Medicine, Sotiria General Hospital, Medical School, National and Kapodistrian University of Athens, 11527 Athens; ${ }^{3}$ Radiotherapy Department, Athens Medical Center, 15125 Athens; ${ }^{4}$ Research Group of Clinical Pharmacology and Pharmacogenomics, Faculty of Pharmacy, School of Health Sciences, National and Kapodistrian University of Athens, 15771 Athens; ${ }^{5}$ Cardio-Thoracic Surgery Department, University Hospital of Heraklion;

${ }^{6}$ Laboratory of Clinical Virology, School of Medicine, University of Crete, 71003 Heraklion, Greece
\end{abstract}

Received August 5, 2021; Accepted October 5, 2021

DOI: $10.3892 / \mathrm{ol} .2021 .13137$

\begin{abstract}
Cancer growth in host tissues features glutamine (gln) depletion over time, decreasing epithelial cells' optimal functioning. In addition, radiotherapy (RT) and/or chemotherapy (CT) cause damage to normal tissues, probably enhanced by this depletion. The present study prospectively examined the effect of gln supplementation on 72 patients with thoracic and upper aerodigestive malignancies (T\&UAM) treated with sequential or concurrent RT-CT or RT alone. All patients received prophylactic gln powder $15 \mathrm{~g}$ bid for the full duration of treatment. The severity of acute radiation toxicities was graded according to the RT Oncology Group/European Organization for Research and Treatment of Cancer criteria. Primary endpoints were the incidence of grade $>2$ toxicities, weight loss and requirement for analgesics, and the secondary
\end{abstract}

Correspondence to: Professor Nikolaos Drakoulis, Research Group of Clinical Pharmacology and Pharmacogenomics, Faculty of Pharmacy, School of Health Sciences, National and Kapodistrian University of Athens, Panepistimiopolis Zografou, 15771 Athens, Greece

E-mail: drakoulis@pharm.uoa.gr

Abbreviations: gln, glutamine; RT, radiotherapy; CT, chemotherapy; H\&NT, head and neck tumors; T\&UAM, thoracic and upper aerodigestive malignancies; TCA, tricarboxylic acid; RCT, randomized controlled trial; LC, lung cancer; ALL, acute lymphoblastic leukemia; ARIE, acute RT-induced esophagitis; NSCLC, non-small cell LC; OM, oral mucositis

Key words: glutamine, chest tumor, lung cancer, head and neck cancer, clinical study, human subjects endpoint was the association of the length of irradiated esophagus from treatment planning with the use of opioids. The incidence of adverse effects was as follows: Grade $>2$ stomatitis, $25.0 \%$; esophagitis, $60.5 \%$; dysphagia, $54.2 \%$; pain, $25.4 \%$; mycosis, $40.8 \%$. Stomatitis grade $>2$ was more frequent in patients with head and neck tumors $(\mathrm{P}<0.001)$ and in those with prior surgery $(\mathrm{P}<0.001)$. Esophagitis $(\mathrm{P}=0.020)$ and dysphagia $(\mathrm{P}=0.008)$ grade $>2$ were more frequent in patients with concurrent RT-CT. Regarding analgesics, $9.9 \%$ of patients received no pain treatment, $56.3 \%$ received simple analgesic therapy and $33.8 \%$ opioids. Patients on opioid therapy had a greater mean length of irradiated esophagus $(\mathrm{P}=0.024)$ or length $>12 \mathrm{~cm}(\mathrm{P}=0.018)$. In $54.2 \%$ of patients, weight loss was observed, particularly with concurrent RT-CT $(\mathrm{P}=0.007)$. Thus, the use of oral gln may have an important role in reducing acute radiation toxicities and weight loss, and in lowering the requirement for analgesics in patients with T\&UAM. Further randomized trials are required to identify the appropriate gln dose, duration of treatment and precise radiation dosimetric parameters in this group of patients. The present clinical trial was retrospectively registered in the ClinicalTrials. gov Protocol Registration and Results System (registration no. NCT05054517/22-09-2021).

\section{Introduction}

Glutamine $(\mathrm{g} \ln )$ is the most abundant free amino acid in the body, held within skeletal muscle cells. Gln is used by the cell for both bioenergetic and biosynthetic needs. Once taken up by the cell, the vast majority of gln is converted to glutamate by mitochondrial glutaminase, an enzyme whose levels are frequently upregulated in tumors and tumor cell lines $(1,2)$.

Proliferatively active cells require a source of carbon and nitrogen for the synthesis of macromolecules. Although most 


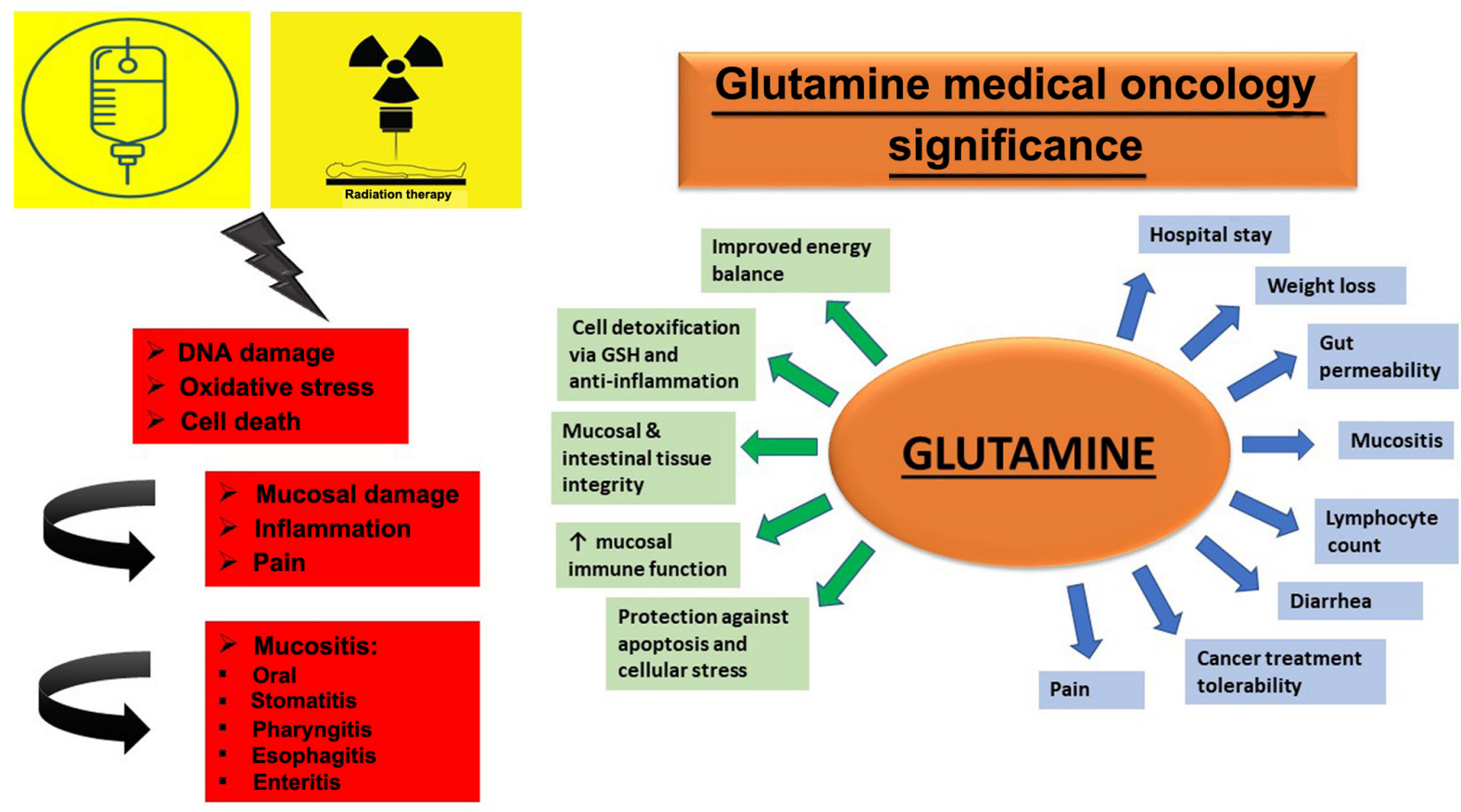

Figure 1. Medical oncology significance of gln. Gln has effects on mucositis/stomatitis, esophagitis, diarrhea, weight loss, gut permeability, lymphocyte count, hospital stay and pain. Gln, glutamine; GSH, glutathione.

tumor cells utilize aerobic glycolysis and shunt metabolites away from mitochondrial oxidative phosphorylation, numerous tumor cells exhibit increased mitochondrial activity. In these cells, gln uptake is markedly enhanced and far exceeds the metabolic requirements of the cell (3).

In the case of tumor growth and proliferation, a single conceptual model of the cancer metabolism program does not exist. Variability exists across different types of cancer in terms of glycolytic and glutaminolytic contribution to malignant proliferation, which allows tumors to utilize different anaplerotic precursors or metabolic platforms as a means of dynamic adaptation under stress (4).

Cancer cells exhibit dysregulation of the proteins/enzymes involved in the key regulatory steps of glucose transport, glycolysis, tricarboxylic acid (TCA) cycle and glutaminolysis, governed not only by oncogenes such as c-Myc but also by hypoxia-inducible factor-1 and loss of function tumor suppressor p53 (5). The MYC oncogene, which serves a critical role in numerous types of human cancer, is considered a master regulator of cell metabolism and proliferation, reprogramming mitochondrial metabolism towards sustaining cellular viability and TCA cycle anaplerosis (6).

Numerous in vitro studies provided evidence that upregulation of the gln pathway provides cancer cells with a variety of essential products to sustain cell proliferation, such as ATP and macromolecules, for biosynthesis. Human cancer cell lines exhibited a 5- to 10-fold faster rate of gln consumption than non-malignant cells (7). It may be inferred that available gln predicts a more aggressive tumor behavior and raises the possibility that nutritional supplementation with gln may stimulate tumor growth by promoting angiogenesis, survival and motility of cancer cells through the activation of $N F-\kappa B(8)$. Several gln analogs have been studied as potential chemotherapeutic (CT) agents in preclinical animal studies and in phase I clinical trials in patients with the rationale to diminish blood gln levels and, thereby, decrease the availability of gln to the tumor; however, the results were disappointing, and studies were discontinued due to side effects (9). On the contrary, in rat model studies, supplemental oral gln improved host tolerance through altering glutathione metabolism and protected normal tissues from CT treatment-related injury (10).

These contradictory results of in vitro and animal studies clearly indicate that reliable information regarding the effects of supplemental gln may only be made based on clinical studies in humans. If gln is not available from exogenous sources, tumor cells may manipulate the host metabolism to cover their needs endogenously. Thus, any measures to establish a gln depletion situation 'artificially' cannot stop or even retard tumor growth (11). Furthermore, the endogenous use of gln by parasitic cancer cells is associated with impaired physiological functions of disturbed mucosal integrity and diminished immune competence (12).

With this hypothesis, within the last two decades, numerous clinical trials evaluated supplemental oral, enteral, or parenteral gln tolerance, safety and effects in various cancer patient groups; dosage, time, and frequency of gln supplementation, as well as cancer type and stage of disease, varied considerably (13). In general, oral/enteral and parenteral gln dipeptide supplementation was safe and well-tolerated, with tumor growth and tumor protein synthesis being unaltered and with no adverse effects on the efficacy of antitumor treatment (14).

Concerning gln supplementation, >50 clinical studies for all cancer types (from the MEDLINE Database between 2000 and 2020) have been performed. For patients with thoracic and upper aerodigestive malignancies (T\&UAM), 22 clinical studies with oral gln supplementation [16 randomized 
Table I. Patient characteristics and features of their disease and treatment.

\begin{tabular}{|c|c|}
\hline Variable & Value \\
\hline Age, years & $65.6 \pm 11.2$ \\
\hline \multicolumn{2}{|l|}{ Sex } \\
\hline Male & $54(75.0)$ \\
\hline Female & $18(25.0)$ \\
\hline \multicolumn{2}{|l|}{ Weight loss after RT } \\
\hline No & $30(42.3)$ \\
\hline Yes & $41(57.7)$ \\
\hline \multicolumn{2}{|l|}{ PS } \\
\hline 0 & $29(40.3)$ \\
\hline 1 & $37(51.4)$ \\
\hline 2 & $6(8.3)$ \\
\hline \multicolumn{2}{|l|}{ Cancer type } \\
\hline Chest tumor & $33(45.8)$ \\
\hline Head \& neck & $39(54.2)$ \\
\hline \multicolumn{2}{|l|}{ Grade } \\
\hline 1 & 7 (11.7) \\
\hline 2 & $24(40.0)$ \\
\hline 3 & $29(48.3)$ \\
\hline \multicolumn{2}{|l|}{ Stage } \\
\hline $\mathrm{I}$ & $11(15.9)$ \\
\hline II & $12(17.4)$ \\
\hline III & $37(53.6)$ \\
\hline IV & $9(13.0)$ \\
\hline Duration of RT, days & $33.6 \pm 13.0$ \\
\hline Total dose, cGY & $5,489.4 \pm 1,196.2$ \\
\hline Irradiation fractions & $26.4 \pm 7.1$ \\
\hline \multicolumn{2}{|l|}{$\begin{array}{l}\text { Length of the radiated } \\
\text { esophagus from } \\
\text { treatment planning }(\mathrm{cm})\end{array}$} \\
\hline$<12$ & $31(43.7)$ \\
\hline$>12$ & $40(56.3)$ \\
\hline Prior surgery & $25(34.7)$ \\
\hline Prior chemotherapy & $31(43.7)$ \\
\hline Concurrent chemotherapy & $27(38.0)$ \\
\hline $\begin{array}{l}\text { Chemotherapy (before and } \\
\text { at the same time as RT) }\end{array}$ & $14(19.7)$ \\
\hline $\begin{array}{l}\text { Chemotherapy only at } \\
\text { the same time as RT }\end{array}$ & $13(18.3)$ \\
\hline Only RT & $27(38.0)$ \\
\hline $\begin{array}{l}\text { Subsequent chemotherapy } \\
\text { after RT }\end{array}$ & $21(29.6)$ \\
\hline \multicolumn{2}{|l|}{ Smoking } \\
\hline No & $19(26.4)$ \\
\hline Yes & $43(59.7)$ \\
\hline Former smoker & $10(13.9)$ \\
\hline Alcohol consumption & $28(41.8)$ \\
\hline Diabetes & $20(31.7)$ \\
\hline Hypertension & $30(54.5)$ \\
\hline
\end{tabular}

Values are expressed as $\mathrm{n}(\%)$ or the mean \pm standard deviation. PS, performance status; RT, radiotherapy.
Table II. Grading system for pain medications.

\begin{tabular}{|c|c|c|}
\hline Grade $^{a}$ & Drug & Group \\
\hline 0 & None & No \\
\hline 1 & Simple analgesics & $\begin{array}{l}\text { Simple analgesics } \\
\text { and/or NSAIDs }\end{array}$ \\
\hline 2 & $\begin{array}{l}\text { Simple analgesics } \\
\text { and NSAIDs }\end{array}$ & $\begin{array}{l}\text { Simple analgesics } \\
\text { and/or NSAIDs }\end{array}$ \\
\hline 3 & $\begin{array}{l}\text { Weak narcotics, } \\
\text { i.e., codeine }\end{array}$ & Opioids \\
\hline 4 & $\begin{array}{l}\text { Narcotics,i.e., } \\
\text { fentanyl patch }\end{array}$ & Opioids \\
\hline
\end{tabular}

${ }^{a}$ World Health Organization's pain relief ladder (17). NSAIDs, nonsteroidal anti-inflammatory drugs.

controlled trials (RCTs), 3 pilot and 3 retrospective studies] evaluated its safety, tolerance and effect on mucositis/stomatitis, esophagitis, pain, weight loss and hospital stay. According to most of the available clinical evidence, gln supplementation may decrease the incidence and/or severity of standard of care treatment-associated toxicities in tumors of the lung and esophagus, as well as head \& neck tumors (H\&NT) $(13,15)$, while dosimetric modality parameters impacting this effect remain to be clarified and this effect remains to be translated into the need for analgesic therapy (Fig. 1).

Therefore, the present study aimed to evaluate the potential effect of oral gln to reduce radiation-induced toxicities, weight loss and pain in patients with T\&UAM. In addition, to define a subgroup of patients who are more likely to benefit from treatment, association with dosimetric parameters predictive of these adverse effects, such as the length of the irradiated esophagus, were determined. The primary endpoints were the incidence of toxicities of grade 2, weight loss and the need for analgesic therapy. The secondary endpoint was the correlation of the length of the irradiated esophagus from radiotherapy (RT) treatment planning with the use of opioids as analgesics.

\section{Materials and methods}

Study subjects. A total of 72 patients with biopsy-confirmed T\&UAM, treated either with sequential or concomitant RT-CT (62\%) or RT alone (38\%) and supplemented with oral gln prior to the initiation of the RT treatment were prospectively recruited from the Department of Radiation Oncology of Athens Medical Center (Athens, Greece) between April 2013 and September 2017. Sample size calculation was not performed a priori since it was restricted by the sample availability. The mean age of the patients was 65.6 \pm 1.2 years (age range, 54-77 years). Most participants were males $(n=54,75 \%)$. Table I provides demographics and clinical characteristics of the patients. The study was approved by the Ethics Committee of the Hospital (approval no. 2281/26-04-2013).

Demographics and clinical characteristics. Patient characteristics and features of their disease and treatment 
Table III. Adverse events and pain treatment.

\begin{tabular}{ll}
\hline Item & $\mathrm{n}(\%)$ \\
\hline
\end{tabular}

Stomatitis, grad
0
1
2
3

$41(60.3)$

$10(14.7)$

$9(13.2)$

8 (11.8)

Esophagitis, grade$$
0
$$$$
1
$$$$
2
$$$$
3
$$

Dysphagia, grade

$$
\begin{aligned}
& 0 \\
& 1 \\
& 2 \\
& 3
\end{aligned}
$$

Pain, grade

0

1

2

3

Mycosis

No

Yes

$20(28.2)$

$28(39.4)$

15 (21.1)

9 (12.9)

23 (32.9)

33 (47.1)

5 (7.1)

8 (11.3)

45 (63.4)

7 (9.9)

11 (15.5)

42 (59.2)

29 (40.8)

At least one adverse

event

No

Yes

Pain treatment

None

Simple analgesics

and opioids

Opioids

Antimycotic treatment

No

Yes

29 (40.8)

Antimycotic prophylaxis

No

$40(61.5)$

$25(38.5)$

are presented in Table I, more than half of the participants $(54.2 \%)$ had H\&NT, while the remaining $(45.8 \%)$ had tumors of the chest, i.e. lung cancer (LC). In addition, $40.0 \%$ of the participants had grade 2 cancer and $53.6 \%$ were in stage III. The mean duration of RT was 33.6 \pm 13.0 days and in $56.3 \%$ of the cases, the length of the irradiated esophagus from treatment planning was $>12 \mathrm{~cm}$. A total of $34.7 \%$ of the patients had previous surgery and $43.7 \%$ had a CT prior to RT. Furthermore, $19.7 \%$ of the patients had CT prior to and at the same time as RT, while $18.3 \%$ had CT only at the same time as RT (concurrent CT-RT). A total of $57.7 \%$ of the participants had lost weight after the RT and the majority had a performance status (PS) of $<2$. Diabetes and hypertension were present in $31.7 \%$ and $54.5 \%$ of the patients, respectively.

Patient treatment. All participants were treated either with sequential or concomitant RT-CT $(62 \%)$ or RT alone $(38 \%)$ and received prophylactic gln powder in doses of $15 \mathrm{~g} 2$ times per day (bid), for the total duration of RT treatment. The radiation technique was three-dimensional conformal RT. Prior to RT, patients had a computerized tomography scan on the region of the body treated using adequate immobilization. Clinical treatment volumes, planning treatment volumes and organs at risk were contoured on each slice $(3 \mathrm{~mm} / 5 \mathrm{~mm})$ with isodose distribution on the nasopharynx or mediastinum, also displaying the length of the irradiated esophagus. 3D plans were generated on a Masterplan (Nucletron Group Ltd.) treatment planning system using the collapsed cone algorithm. Irradiation was then performed using a 6MV Primus (Siemens AG) linear accelerator with a total dose of 50-70 Gy and 2-2.5 Gy/fraction. Concurrent CT consisted of low-dose weekly cisplatin in $38 \%$ of the patients.

The severity of different acute radiation toxicities was graded according to the RT Oncology Group/European Organization for Research and Treatment of Cancer criteria (16). The median follow-up of the acute radiation toxicities was one month, as for the duration of gln supplementation. For each patient, the medical history was reviewed and clinical examination was performed.

Smoking history and alcohol use were marked as risk factors and diabetes and hypertension as comorbidities, while stomatitis, esophagitis, dysphagia, pain and mycosis were reported as acute adverse events of RT.

Medications for pain control were prescribed when the patient became symptomatic. Antimycotic treatment was given in clinical fungal infection, while antimycotic prophylactic therapy was given in patients with a high probability of displaying one [patients with a high grade of oral mucositis (OM), pain and dysphagia]. Table II provides the grading system for pain medications, following the World Health Organization's pain relief ladder (17).

Statistical analysis. Quantitative variables are presented as mean values \pm standard deviation, while qualitative variables are presented as frequencies with percentages (\%). For comparison of proportions, Pearson's $\chi^{2}$ and Fisher's exact tests were used. Student's t-tests were applied for comparison of continuous variables between the groups. Logistic regression analysis in a stepwise method (for entry, $\mathrm{P}=0.05$; for removal, $\mathrm{P}=0.10$ ) was performed to identify independent factors associated with weight loss after RT. Adjusted odds ratios (OR) with the corresponding 95\% confidence intervals $(95 \% \mathrm{CI})$ were calculated from logistic regression analyses. All reported P-values were two-tailed and $\mathrm{P}<0.05$ was considered to indicate statistical significance. Analyses were performed using SPSS statistical software (version 19.0; IBM Corporation). 


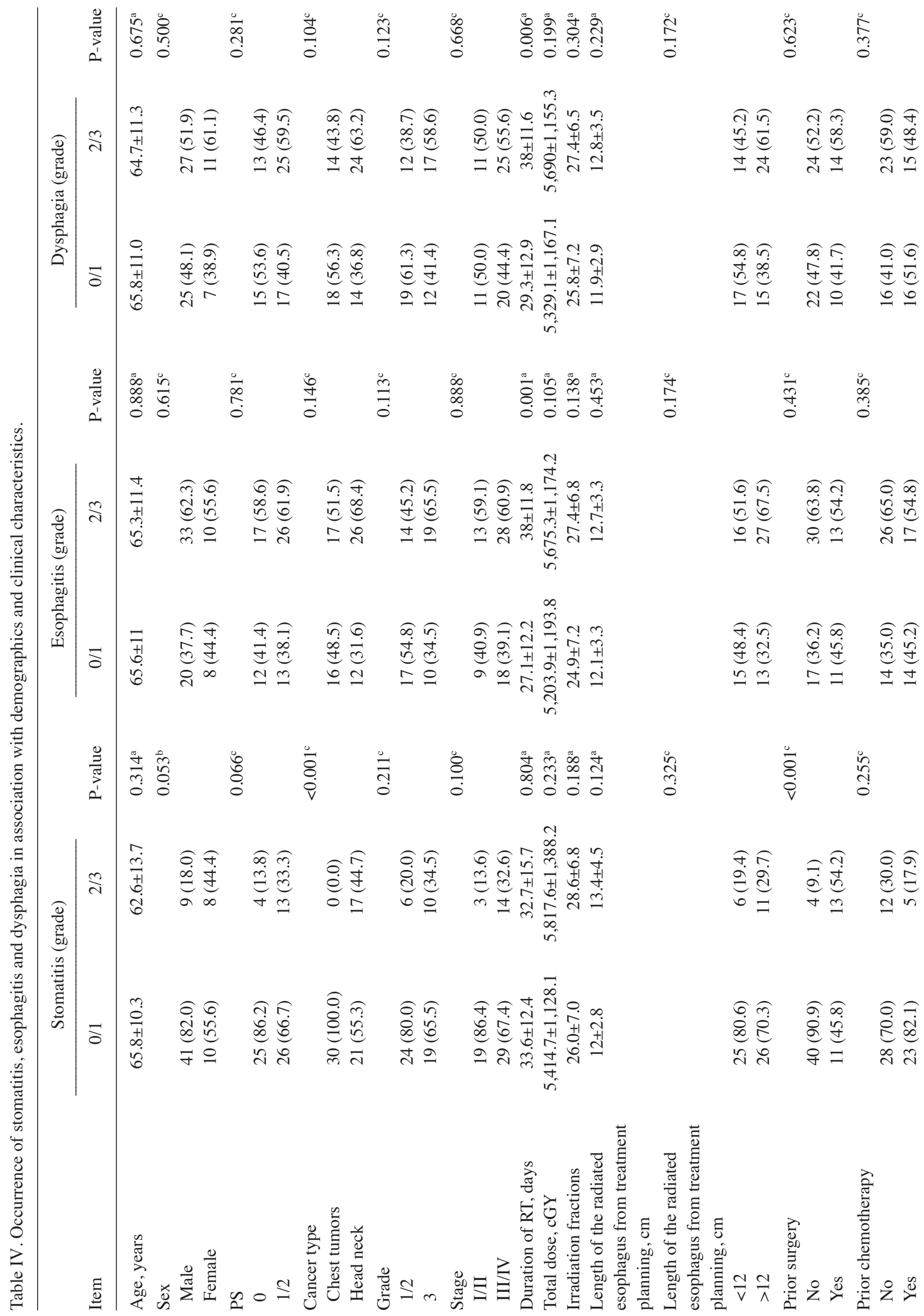




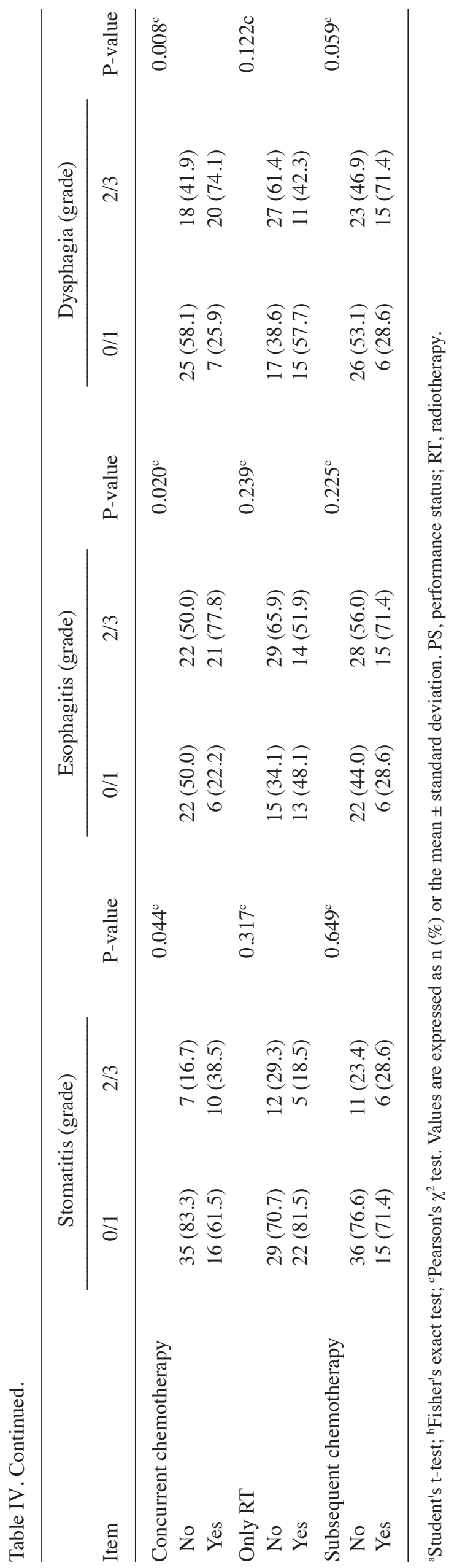

\section{Results}

Adverse events and pain treatment. The frequencies of patients with adverse events and pain treatment are presented in Table III. In $39.7 \%$ of the patients, stomatitis was grade 1 or more and the frequencies for esophagitis, dysphagia and pain were $88.7,87.1$ and $88.7 \%$, respectively. Mycosis was present in $40.8 \%$ of the patients (all of them manages with antimycotic treatment) and $89.6 \%$ had at least one adverse event. Opioids were used in $16.9 \%$ of the cases and in $16.9 \%$ of the cases, the combination of both simple analgesics and opioids was utilized. In total, opioids were used in $33.8 \%$ of the study population.

Association between adverse events and patient characteristics. The occurrence of stomatitis, esophagitis and dysphagia in association with demographics and clinical characteristics are presented in Table IV. Stomatitis grade 2 to 3 was more frequent in $\mathrm{H} \& \mathrm{NT}(\mathrm{P}=0.001)$, in those having previous surgery (OR: 11.818 ; 95\% CI: 3.207-43.550; $\mathrm{P}<0.001)$ and in those having concurrent CT (OR: 3.125; 95\% CI: 1.007-9.699; $\mathrm{P}=0.044$ ). Esophagitis (OR: 3.500; 95\% CI: 1.185-10.335; $\mathrm{P}=0.020$ ) and dysphagia (OR: 3.968; 95\% CI: 1.385-11.369; $\mathrm{P}=0.008$ ) grade 2 to 3 was more frequent in those having concurrent CT-RT (Table SI). In addition, the duration of RT was indicated to be significantly greater in patients with esophagitis $(\mathrm{P}=0.001)$ and dysphagia $(\mathrm{P}=0.006)$ grades 2 to 3 . Furthermore, it was indicated (data not shown) that patients who consume alcohol had grade 2-3 esophagitis in a significantly greater percentage compared to the ones who did not consume any alcohol (78.6 vs. $48.7 \%$; $\mathrm{P}=0.013)$. In addition, patients who consumed alcohol had grade 2-3 dysphagia in a significantly greater percentage compared to the ones who did not consume any alcohol (71.4 vs. $42.1 \% ; \mathrm{P}=0.018$ ). In addition, grade 2-3 dysphagia was present in a significantly greater percentage of patients with diabetes than in those without diabetes (70.0 vs. $38.1 \%$; $\mathrm{P}=0.019$ ).

Pain and opioid use. Table $\mathrm{V}$ presents the frequencies of patients with pain, mycosis and at least one adverse event according to demographics and clinical characteristics. Pain grade 2 to 3 (OR: 5.067; 95\% CI: $1.608-15.967$; $\mathrm{P}=0.004)$ and mycosis (OR: 6.000; 95\% CI: 2.096-17.173; $\mathrm{P}=0.001$ ) were more frequent in those having concurrent CT-RT. Mycosis was more frequent in cases with PS 1 to 2 (OR: 4.640; 95\% CI: $1.569-13.728 ; \mathrm{P}=0.004$ ). Pain grade 2 to 3 (OR: $3.417 ; 95 \%$ CI: $1.108-10.553 ; \mathrm{P}=0.028$ ) and mycosis (OR: 4.667; 95\% CI: 1.568-13.886; $\mathrm{P}=0.004$ ) were also more frequent in those having $\mathrm{CT}$ after RT, while the proportion of subjects with mycosis was lower in those treated with RT only (OR: 0.350 ; $95 \%$ CI: $0.123-0.994$; $\mathrm{P}=0.045$; Table SI).

A total of 40 patients $(56.3 \%)$ received only simple analgesics for pain treatment, while opioid therapy with or without analgesics was taken by 24 patients (33.8\%). A total of 7 patients (9.9\%) did not report any pain and received no pain treatment (Table III). The mean length of the irradiated esophagus from treatment planning $(\mathrm{P}=0.024)$ and duration of $\mathrm{RT}(\mathrm{P}=0.023)$ were significantly greater in those to whom opioids were administered (Table VI). The use of opioids was 


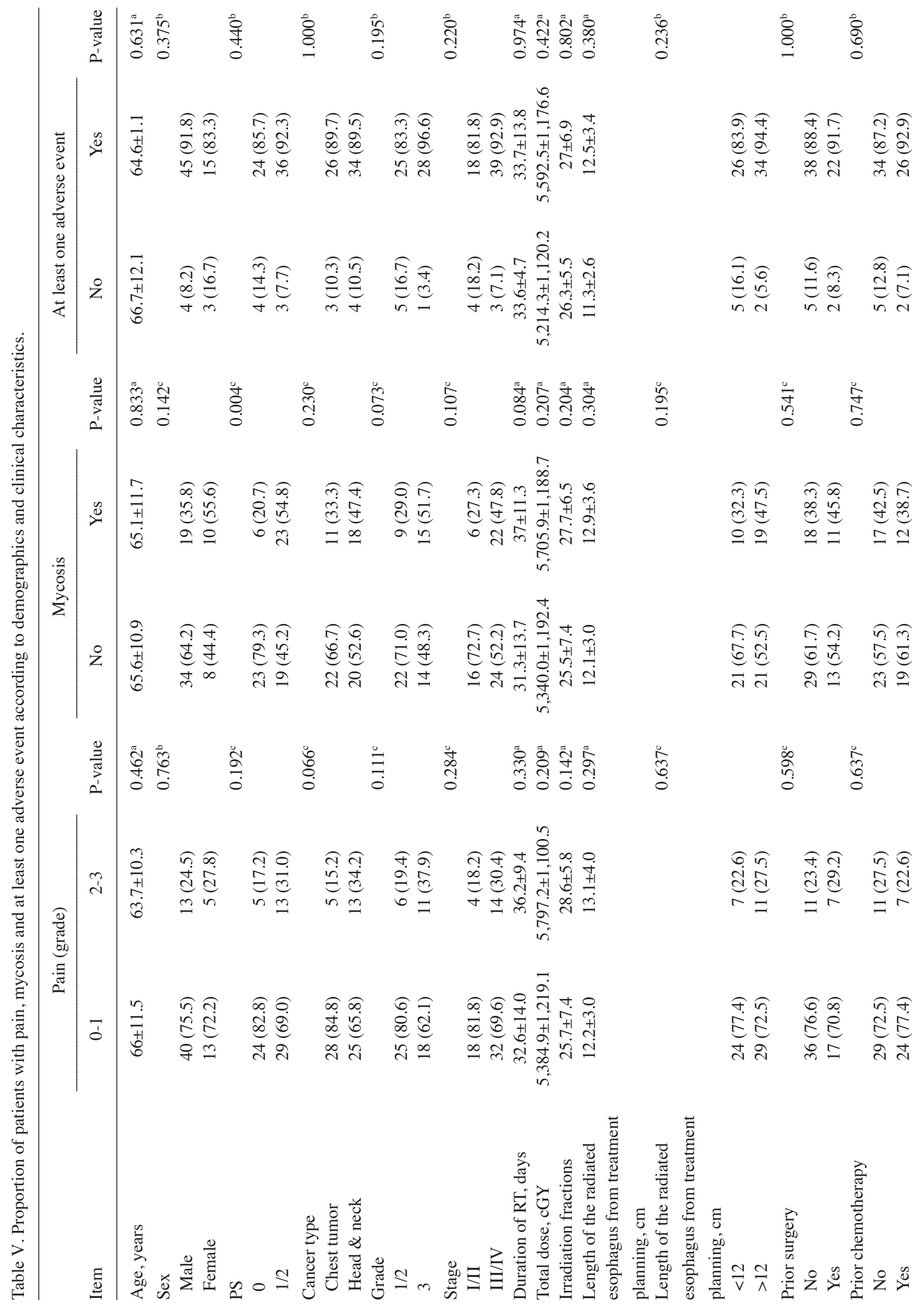


more frequent in cases where the length of the irradiated esophagus from treatment planning was $>12 \mathrm{~cm}(\mathrm{P}=0.018$; Table $\mathrm{VI})$. Contrarily, the use of opioids was less frequent in patients with stomatitis grade 0-1 (OR: 6.667; 95\% CI: 2.012-22.085; $\mathrm{P}=0.001)$ and in patients with pain grade $0-1$ (OR: 4.835; 95\% CI: 1.553-15.052; $\mathrm{P}=0.005$; Table VII).

Weight loss. The percentages of patients who lost weight after RT are presented in Table VIII. Significantly greater were weight loss percentages in patients with H\&NT (OR: 2.6; 95\% CI: 0.987-6.846; $\mathrm{P}=0.051)$, in those who had concurrent CT (OR: 4.2; 95\% CI: 1.420-12.419; $\mathrm{P}=0.007$ ) and in those who had CT after the RT (OR: 3.2; 95\% CI: 1.016-10.076; $\mathrm{P}=0.041)$. In addition, the duration of $\mathrm{RT}(\mathrm{P}=0.001)$, total dose in $\mathrm{cGY}(\mathrm{P}<0.001)$, irradiation fractions $(\mathrm{P}<0.001)$ and length of the irradiated esophagus from treatment planning $(\mathrm{P}=0.009)$ were significantly greater in patients with weight loss. When multiple logistic regression analysis was applied with weight loss as the dependent variable, a significant association with the total dose of RT and concurrent CT-RT was observed and larger doses of RT resulted in a higher likelihood of weight loss (OR: 1.08; 95\% CI: 1.02-1.14; $\mathrm{P}=0.007$ ). In addition, patients with concurrent CT-RT had a higher weight loss likelihood (OR: 3.21; 95\% CI: 1.03-10.0; $\mathrm{P}=0.044)$.

\section{Discussion}

Glutamine is the most abundant amino acid in the body. A tumor may act as a gln trap by depleting host gln stores and resulting in cachexia. This fact led to the development of one of the first successful metabolic therapies, L-asparaginase, for the treatment of acute lymphoblastic leukemia (ALL) 30 years ago. L-asparaginase is able to deplete plasma asparagine and gln, while ALL cells, which require large amounts of gln, are affected by this treatment (18). However, L-asparaginase has only been proven to be effective in ALL and certain natural killer/T-cell lymphomas, with no effect in acute myeloid leukemia, non-Hodgkin's lymphoma and solid tumors (19). Recent studies eventually provided evidence that explained this lack of antitumor effect of gln deprivation, by suggesting that various tumor types may reside in an environment where gln is profoundly limited and they adapted to this by pursuing strategies in order to sustain their growth and survival (20-22). In most glutamine-deprived cell lines, induction of de novo biosynthesis of gln or acquisition of gln through catabolism of extracellular and intracellular proteins has been indicated to provide a source of missing gln for cells (23).

The variation of nutrient acquisition in amino acid-replete and amino acid-starved settings varies among different cancer types. For instance, the response of human breast carcinoma cells to gln deprivation was observed to exert the same effects as lactate accumulation in tumors: Increased NF- $\mathrm{\kappa B}$ activity and subsequent stimulation of IL-8/C-X-C motif chemokine ligand 8 expression, which, in turn, promotes angiogenesis (24). In a recent study, gln supplementation in a rat model blocked melanoma tumor growth by suppressing epigenetically activated oncogenic pathways (25). These contradictory results from in vitro, animal and clinical studies clearly indicate that reliable information about the effects of supplemental gln may only be obtained based on in vivo studies for each cancer type 
Table VI. Use of opioids according to demographics and clinical characteristics.

\begin{tabular}{|c|c|c|c|}
\hline \multirow[b]{2}{*}{ Item } & \multicolumn{2}{|c|}{ Opioids } & \multirow[b]{2}{*}{ P-value } \\
\hline & No & Yes & \\
\hline Age, years & $64.9 \pm 10.6$ & $66.3 \pm 12.4$ & $0.621^{\mathrm{a}}$ \\
\hline $\begin{array}{l}\text { Sex } \\
\text { Male } \\
\text { Female }\end{array}$ & $\begin{array}{l}34(64.2) \\
13(72.2)\end{array}$ & $\begin{array}{r}19(35.8) \\
5(27.8)\end{array}$ & $0.532^{\mathrm{b}}$ \\
\hline $\begin{array}{l}\text { PS } \\
0 \\
1 / 2\end{array}$ & $\begin{array}{l}22(75.9) \\
25(59.5)\end{array}$ & $\begin{array}{r}7(24.1) \\
17(40.5)\end{array}$ & $0.153^{b}$ \\
\hline $\begin{array}{l}\text { Cancer type } \\
\text { Chest tumor } \\
\text { Head \& neck }\end{array}$ & $\begin{array}{l}24(72.7) \\
23(60.5)\end{array}$ & $\begin{array}{r}9(27.3) \\
15(39.5)\end{array}$ & $0.278^{\mathrm{b}}$ \\
\hline $\begin{array}{l}\text { Grade } \\
1 / 2 \\
3\end{array}$ & $\begin{array}{l}19(61.3) \\
18(62.1)\end{array}$ & $\begin{array}{l}12(38.7) \\
11(37.9)\end{array}$ & $0.951^{\mathrm{b}}$ \\
\hline $\begin{array}{l}\text { Stage } \\
\text { I/II } \\
\text { III/IV }\end{array}$ & $\begin{array}{l}17(77.3) \\
27(58.7)\end{array}$ & $\begin{array}{r}5(22.7) \\
19(41.3)\end{array}$ & $0.134^{\mathrm{b}}$ \\
\hline $\begin{array}{l}\text { Duration of RT, days } \\
\text { Total dose, cGY } \\
\text { Irradiation fractions }\end{array}$ & $\begin{array}{c}36.2 \pm 12.3 \\
5,511.1 \pm 1,123.4 \\
26.6 \pm 6.8\end{array}$ & $\begin{array}{c}28.6 \pm 13.1 \\
5,447.1 \pm 1,351.9 \\
26.2 \pm 7.8\end{array}$ & $\begin{array}{l}0.023^{\mathrm{a}} \\
0.833^{\mathrm{a}} \\
0.847^{\mathrm{a}}\end{array}$ \\
\hline $\begin{array}{l}\text { Length of the radiated } \\
\text { esophagus from treatment } \\
\text { planning, cm }\end{array}$ & $11.8 \pm 2.9$ & $13.6 \pm 3.6$ & $0.024^{\mathrm{a}}$ \\
\hline $\begin{array}{l}\text { Length of the radiated } \\
\text { esophagus from treatment } \\
\text { planning }(\mathrm{cm})\end{array}$ & & & $0.018^{\mathrm{b}}$ \\
\hline $\begin{array}{l}<12 \\
>12\end{array}$ & $\begin{array}{l}24(77.4) \\
23(57.5)\end{array}$ & $\begin{array}{r}7(22.6) \\
17(42.5)\end{array}$ & \\
\hline $\begin{array}{l}\text { Prior surgery } \\
\text { No } \\
\text { Yes }\end{array}$ & $\begin{array}{l}33(70.2) \\
14(58.3)\end{array}$ & $\begin{array}{l}14(29.8) \\
10(41.7)\end{array}$ & $0.317^{\mathrm{b}}$ \\
\hline $\begin{array}{l}\text { Prior chemotherapy } \\
\text { No } \\
\text { Yes }\end{array}$ & $\begin{array}{l}28(70) \\
19(61.3)\end{array}$ & $\begin{array}{l}12(30) \\
12(38.7)\end{array}$ & $0.442^{b}$ \\
\hline $\begin{array}{l}\text { Concurrent chemotherapy } \\
\text { No } \\
\text { Yes }\end{array}$ & $\begin{array}{l}30(68.2) \\
17(63)\end{array}$ & $\begin{array}{l}14(31.8) \\
10(37)\end{array}$ & $0.652^{b}$ \\
\hline $\begin{array}{l}\text { Only RT } \\
\text { No } \\
\text { Yes }\end{array}$ & $\begin{array}{l}27(61.4) \\
20(74.1)\end{array}$ & $\begin{array}{r}17(38.6) \\
7(25.9)\end{array}$ & $0.272^{b}$ \\
\hline $\begin{array}{l}\text { Subsequent chemotherapy } \\
\text { No } \\
\text { Yes }\end{array}$ & $\begin{array}{l}33(66) \\
14(66.7)\end{array}$ & $\begin{aligned} 17 & (34) \\
7 & (33.3)\end{aligned}$ & $0.957^{\mathrm{b}}$ \\
\hline
\end{tabular}

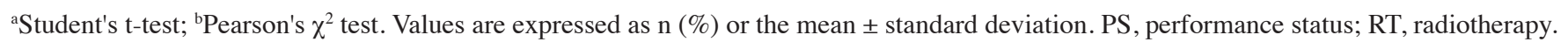

separately (26). Particularly for solid tumors, supplementation of gln was indicated to decrease tumor growth through stimulation of the immune system and protection of mucosal integrity (27).
Treatment for H\&NT primarily involves three modalities: Surgery, RT and CT, administered alone or in combination. RT alone is the most common treatment for certain types of H\&NT, such as cancer of the nasopharynx, larynx and 
Table VII. Use of opioids according to the presence of adverse events.

\begin{tabular}{|c|c|c|c|}
\hline \multirow[b]{2}{*}{ Item } & \multicolumn{2}{|c|}{ Opioids } & \multirow[b]{2}{*}{ P-value } \\
\hline & No & Yes & \\
\hline $\begin{array}{l}\text { Stomatitis, } \\
\text { grade }\end{array}$ & & & $0.001^{\mathrm{a}}$ \\
\hline $0 / 1$ & $40(87.0)$ & $11(50.0)$ & \\
\hline $2 / 3$ & $6(13.0)$ & $11(50.0)$ & \\
\hline $\begin{array}{l}\text { Esophagitis, } \\
\text { grade }\end{array}$ & & & $0.075^{\mathrm{a}}$ \\
\hline $0 / 1$ & $22(46.8)$ & $6(25.0)$ & \\
\hline $2 / 3$ & $25(53.2)$ & $18(75.0)$ & \\
\hline $\begin{array}{l}\text { Dysphagia, } \\
\text { grade }\end{array}$ & & & $0.623^{\mathrm{a}}$ \\
\hline $0 / 1$ & $22(47.8)$ & $10(41.7)$ & \\
\hline $2 / 3$ & $24(52.2)$ & $14(58.3)$ & \\
\hline $\begin{array}{l}\text { Pain, } \\
\text { grade }\end{array}$ & & & $0.005^{\mathrm{a}}$ \\
\hline $0 / 1$ & $40(85.1)$ & $13(54.2)$ & \\
\hline $2 / 3$ & 7 (14.9) & $11(45.8)$ & \\
\hline Mycosis & & & $0.103^{\mathrm{a}}$ \\
\hline No & $31(66.0)$ & $11(45.8)$ & \\
\hline Yes & $16(34.0)$ & $13(54.2)$ & \\
\hline $\begin{array}{l}\text { At least } \\
\text { one adverse } \\
\text { event }\end{array}$ & & & $0.412^{\mathrm{b}}$ \\
\hline No & $6(13.3)$ & $1(4.5)$ & \\
\hline Yes & 39 (86.7) & $21(95.5)$ & \\
\hline
\end{tabular}

${ }^{\text {aPearson's }} \chi^{2}$ test; ${ }^{\text {b}}$ Fisher's exact test. Values are expressed as $\mathrm{n}(\%)$.

oropharynx (28). The therapeutic strategies employed for resectable stage III non-small cell LC (NSCLC) include surgical resection with adjuvant $\mathrm{CT}$ and sequential RT, preoperative $\mathrm{CT}$ with adjuvant RT, preoperative $\mathrm{CT}$ and $\mathrm{RT}$. In most patients with stage III NSCLC, the tumors are unresectable and are treated with CT and RT therapy, frequently referred to as combined modality therapy or concurrent CT-RT. For stage IV NSCLC, treatment is based on systematic $\mathrm{CT}+$ palliative RT (29). In the present study, patients were treated with sequential or concurrent CT-RT (38\%) or RT alone $(38 \%)$ classified as stage III in the majority of subjects $(53.6 \%)$.

According to the literature, gln doses of up to $40 \mathrm{~g} / \mathrm{day}$ via total parenteral nutrition and up to $30 \mathrm{~g} /$ day taken orally in divided doses were determined to be a safe and effective treatment for mucositis and stomatitis (7). All study patients received oral gln supplementation (15 g bid) and no gln intolerance or toxicity was reported.

In H\&NT patients on RT, oral gln was applied as a 'swish and swallow' therapy with the purpose to increase enterocyte contact and decrease the severity and duration of stomatitis. This rationale implies that not only the dose, but also effective penetration and local mucosal cell uptake of glutamine are probably important (13). In the published studies, different gln supplementation regimens were implemented, from the first round of conventional CT and/or RT until two weeks post-therapy, with positive results indicating either a shorter duration or reduced severity of OM (30-39).

For patients with chest tumors and LC, as far as esophagitis is concerned, the same beneficial results were indicated in most studies (40-44). First, a pilot study by Algara et al (40) assessed the usefulness of oral gln to prevent RT-CT-induced esophagitis, along with a dosimetric parameter of V50 predictive of esophagitis and its duration. The randomized trials that followed $(41,42)$ evaluated the efficacy of oral gln in the prevention of acute RT-induced esophagitis (ARIE) and weight loss in patients with LC. In a study by Topkan et al (41), $\mathrm{V} 55$, the mean volume of the lung receiving $55 \mathrm{~Gy}$, was the only dosimetric parameter correlated with the severity of ARIE in gln-free patients and it was concluded that gln may be beneficial in the prevention of ARIE and weight loss in patients with LC undergoing thoracic irradiation.

According to the results of the present study, the adverse event of stomatitis grade 2 to 3 was significantly associated with the cancer type; it was observed more frequently in patients with $\mathrm{H} \& \mathrm{NT}(\mathrm{P}=0.001)$, and with modality treatment; previous surgery $(\mathrm{P}<0.001)$ and concurrent $\mathrm{CT}(\mathrm{P}=0.044)$. Concerning the adverse events of esophagitis and dysphagia, both were significantly associated with concurrent CT-RT ( $\mathrm{P}=0.020$ and $\mathrm{P}=0.008$, respectively).

Published data so far regarding gln supplementation focused on depicting the decrease in the incidence and/or severity of standard of care treatment-associated toxicities in tumors of the lung and esophagus, as well as H\&NT $(13,15)$. For the first time, to the best of our knowledge, the present study determined a dosimetric parameter, such as the irradiated esophagus length from treatment planning, to be correlated with analgesic therapy and weight loss. In patients who used opioids, the mean length of the irradiated esophagus from treatment planning $(\mathrm{P}=0.024)$ and duration of $\mathrm{RT}(\mathrm{P}=0.023)$ were significantly greater. In addition, the use of opioids was more frequent in cases where the length of the irradiated esophagus from treatment planning was $>12 \mathrm{~cm}(\mathrm{P}=0.018)$. For weight loss after RT, there was also significant association with duration of RT $(\mathrm{P}=0.001)$, total dose $\mathrm{cGY}(\mathrm{P}<0.001)$, irradiation fractions $(\mathrm{P}<0.001)$ and length of irradiated esophagus from treatment planning $(\mathrm{P}=0.009)$ and concurrent or subsequent CT $(\mathrm{P}=0.007$ and $\mathrm{P}=0.041$, respectively). The key findings and features of the present study are summarized in Fig. 2.

The present study was not without limitations. For example, all patients received the same dose of oral gln, and no comparison to a control group (taking no $\mathrm{g} \ln$ ), was made. Thus, further case-control studies with larger sample sizes are required to validate the results presented here.

In conclusion, the use of oral gln supplementation may have an important role in reducing acute radiation toxicities, weight loss and the need for analgesics in patients with T\&UAM, mainly if the treatment plan includes CT and RT. Most of the clinical trials evaluating the use of oral gln in chest and $\mathrm{H} \& \mathrm{~N}$ tumors had positive results regarding its protective effect 
Table VIII. Weight loss after RT according to demographics and clinical characteristics.

\begin{tabular}{|c|c|c|c|}
\hline \multirow[b]{2}{*}{ Item } & \multicolumn{2}{|c|}{ Weight loss after RT } & \multirow[b]{2}{*}{ P-value } \\
\hline & No & Yes & \\
\hline Age, years & $66.2 \pm 11.6$ & $64.8 \pm 10.9$ & $0.613^{\mathrm{a}}$ \\
\hline Sex & & & $0.441^{\mathrm{b}}$ \\
\hline Male & $21(39.6)$ & $32(60.4)$ & \\
\hline Female & $9(50.0)$ & $9(50.0)$ & \\
\hline PS & & & $0.393^{\mathrm{b}}$ \\
\hline 0 & $14(48.3)$ & $15(51.7)$ & \\
\hline $1 / 2$ & $16(38.1)$ & $26(61.9)$ & \\
\hline Cancer type & & & $0.051^{\mathrm{b}}$ \\
\hline Chest tumor & $18(54.5)$ & $15(45.5)$ & \\
\hline Head \& neck & $12(31.6)$ & $26(68.4)$ & \\
\hline Grade & & & $0.058^{\mathrm{b}}$ \\
\hline $1 / 2$ & $16(51.6)$ & $15(48.4)$ & \\
\hline 3 & $8(27.6)$ & $21(72.4)$ & \\
\hline Stage & & & $0.697^{\mathrm{b}}$ \\
\hline I/II & $8(36.4)$ & $14(63.6)$ & \\
\hline III/IV & $19(41.3)$ & $27(58.7)$ & \\
\hline Duration of RT, days & $27.6 \pm 13.3$ & $37.7 \pm 11.3$ & $0.001^{\mathrm{a}}$ \\
\hline Total dose, cGY & $4,919.7 \pm 1,324.7$ & $5,906.3 \pm 900.0$ & $<0.001^{\mathrm{a}}$ \\
\hline Irradiation fractions & $23.0 \pm 7.8$ & $28.9 \pm 5.3$ & $<0.001^{\mathrm{a}}$ \\
\hline $\begin{array}{l}\text { Length of the radiated } \\
\text { esophagus from treatment } \\
\text { planning, cm }\end{array}$ & $11.3 \pm 2.3$ & $13.3 \pm 3.6$ & $0.009^{\mathrm{a}}$ \\
\hline $\begin{array}{l}\text { Length of the radiated } \\
\text { esophagus from treatment } \\
\text { planning, cm }\end{array}$ & & & $0.059^{\mathrm{b}}$ \\
\hline$<12$ & $17(54.8)$ & $14(45.2)$ & \\
\hline$>12$ & $13(32.5)$ & $27(67.5)$ & \\
\hline Prior surgery & & & $0.663^{\mathrm{b}}$ \\
\hline No & $19(40.4)$ & $28(59.6)$ & \\
\hline Yes & $11(45.8)$ & $13(54.2)$ & \\
\hline Prior chemotherapy & & & $0.160^{\mathrm{b}}$ \\
\hline No & $14(35.0)$ & $26(65.0)$ & \\
\hline Yes & $16(51.6)$ & $15(48.4)$ & \\
\hline Concurrent chemotherapy & & & $0.007^{\mathrm{b}}$ \\
\hline No & $24(54.5)$ & $20(45.5)$ & \\
\hline Yes & $6(22.2)$ & $21(77.8)$ & \\
\hline Only RT & & & $0.431^{\mathrm{b}}$ \\
\hline No & $17(38.6)$ & $27(61.4)$ & \\
\hline Yes & $13(48.1)$ & $14(51.9)$ & \\
\hline Subsequent chemotherapy & & & $0.041^{\mathrm{b}}$ \\
\hline No & $25(50.0)$ & $25(50.0)$ & \\
\hline Yes & $5(23.8)$ & $16(76.2)$ & \\
\hline
\end{tabular}

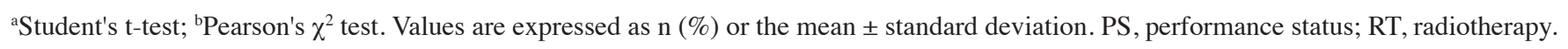

on the mucositis, esophagitis and weight loss level (30-44). The favorable efficacy and low toxicity of oral gln observed in clinical trials provide a strong rationale for large RCTs in patients with cancer receiving RT and/or CT $(45,46)$. Recent 


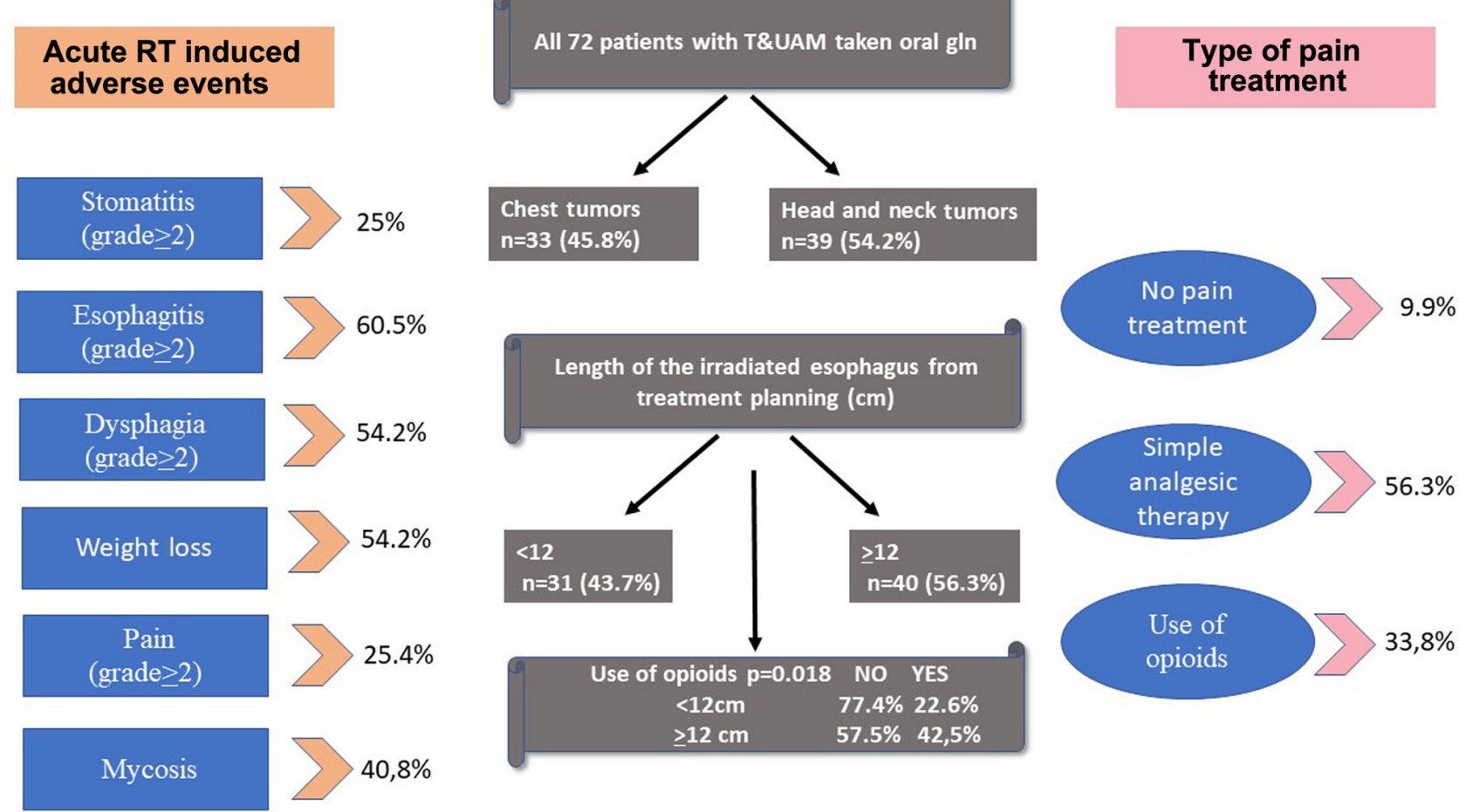

Figure 2. Acute RT-induced adverse events and type of treatment. Percentages of acute adverse events in 72 patients with T\&UAM who took oral gln powder at doses of $15 \mathrm{~g} 2$ times per day for the total duration of radiation treatment. T\&UAM, thoracic and upper aerodigestive malignancies; RT, radiotherapy; gln, glutamine.

meta-analyses specifically focusing on $\mathrm{OM}$ in such groups of patients concluded that gln reduces the severity of $\mathrm{OM}$ and the incidence of severe OM (grade 3 and 4) (47,48). In addition, gln reduced the incidence of opioid analgesic use, feeding tube use, hospitalization and treatment interruption caused by OM (46).

The present study revealed dosimetric parameters, including the total RT dose, the irradiated esophagus length, the concurrent $\mathrm{CT}$ regimen and the radiation techniques applied, which influenced the incidence and severity of RT toxicities. Further RCTs will help comprehensively analyze precise dosimetric parameters from RT treatment planning, and indicate the group of patients most likely to benefit from gln supplementation. In addition, RCTs will help identify the appropriate individualized dose and duration of treatment for gln supplementation according to the specific cancer type and the applied therapeutic modality in order to optimize its protective effect, to reduce the severity and duration of RT toxicities, relieving the degree of mucosal pain.

\section{Acknowledgements}

Not applicable.

\section{Funding}

No funding was received.

\section{Availability of data and materials}

The datasets used and/or analyzed during the current study are available from the corresponding author on reasonable request.

\section{Authors' contributions}

LV and NS contributed to the conception and design of the study. ND supervised the study. ND and LV confirm the authenticity of all the raw data. AP was involved in the patients' clinical history and data acquisition and wrote the manuscript. $\mathrm{LV}$ was involved in the patient recruitment process and in the collection of the subjects' medical files and their evaluation. AP and MP analyzed the data. ND, AC, DAS, GL and SK reviewed and edited the manuscript, and contributed to the interpretation of the data. All authors have read and approved the final manuscript.

\section{Ethics approval and consent to participate}

The present study was approved by the Ethics Committee of Athens Medical Center (Athens, Greece; approval no. 2281/26-04-2013) and written informed consent was provided by all participants prior to the study start.

\section{Patient consent for publication}

Not applicable.

\section{Competing interests}

DAS is the Editor-in-Chief for the journal, but had no personal involvement in the reviewing process, or any influence in terms of adjudicating on the final decision, for this article. The other authors declare that they have no competing interests. 


\section{References}

1. DeBerardinis RJ and Cheng T: Q's next: The diverse functions of glutamine in metabolism, cell biology and cancer. Oncogene 29: 313-324, 2010

2. Levine AJ and Puzio-Kuter AM: The control of the metabolic switch in cancers by oncogenes and tumor suppressor genes Science 330: 1340-1344, 2010

3. Barger JF and Plas DR: Balancing biosynthesis and bioenergetics: Metabolic programs in oncogenesis. Endocr Relat Cancer 17: R287-R304, 2010

4. Cantor JR and Sabatini DM: Cancer cell metabolism: One hallmark, many faces. Cancer Discov 2: 881-898, 2012.

5. Liu W, Le A, Hancock C, Lane AN, Dang CV, Fan TW-M and Phang JM: Reprogramming of proline and glutamine metabolism contributes to the proliferative and metabolic responses regulated by oncogenic transcription factor c-MYC. Proc Natl Acad Sci USA 109: 8983-8988, 2012.

6. Chen JQ and Russo J: Dysregulation of glucose transport, glycolysis, TCA cycle and glutaminolysis by oncogenes and tumor suppressors in cancer cells. Biochim Biophys Acta 1826: 370-384, 2012

7. Kuhn KS, Muscaritoli M, Wischmeyer P and Stehle P: Glutamine as indispensable nutrient in oncology: Experimental and clinical evidence. Eur J Nutr 49: 197-210, 2010.

8. Polet $\mathrm{F}$ and Feron O: Endothelial cell metabolism and tumour angiogenesis: Glucose and glutamine as essential fuels and lactate as the driving force. J Intern Med 273: 156-165, 2013.

9. Ahluwalia GS, Grem JL, Hao Z and Cooney DA: Metabolism and action of amino acid analog anti-cancer agents. Pharmacol Ther 46: 243-271, 1990 .

10. Rubio IT, Cao Y, Hutchins LF, Westbrook KC and Klimberg VS: Effect of glutamine on methotrexate efficacy and toxicity. Ann Surg 227: 772-778, discussion 778-780, 1998.

11. Cluntun AA, Lukey MJ, Cerione RA and Locasale JW: Glutamine Metabolism in Cancer: Understanding the Heterogeneity. Trends Cancer 3: 169-180, 2017.

12. Choi YK and Park KG: Targeting Glutamine Metabolism for Cancer Treatment. Biomol Ther (Seoul) 26: 19-28, 2018.

13. Anderson PM and Lalla RV: Glutamine for Amelioration of Radiation and Chemotherapy Associated Mucositis during Cancer Therapy. Nutrients 12: 1675, 2020.

14. Savarese DM, Savy G, Vahdat L, Wischmeyer PE and Corey B Prevention of chemotherapy and radiation toxicity with glutamine. Cancer Treat Rev 29: 501-513, 2003.

15. Papanikolopoulou A, Syrigos KN and Drakoulis N: The role of glutamine supplementation in thoracic and upper aerodigestive malignancies. Nutr Cancer 67: 231-237, 2015.

16. Cox JD, Stetz J and Pajak TF: Toxicity criteria of the Radiation Therapy Oncology Group (RTOG) and the European Organization for Research and Treatment of Cancer (EORTC). Int J Radiat Oncol Biol Phys 31: 1341-1346, 1995.

17. Subramaniam AV, Salem Yehya AH and Oon CE: Molecular Basis of Cancer Pain Management: An Updated Review. Medicina (Kaunas) 55: 584, 2019.

18. van den Berg H: Asparaginase revisited. Leuk Lymphoma 52 168-178, 2011

19. Jaffe N, Traggis D, Das L, Moloney WC, Hann HW, Kim BS and Nair R: L-asparaginase in the treatment of neoplastic diseases in children. Cancer Res 31: 942-949, 1971.

20. Jia ZY, Shen TY, Jiang W and Qin HL: Identification of molecular mechanisms of glutamine in pancreatic cancer. Oncol Lett 14: 6395-6402, 2017.

21. Stanciu AE, Zamfir-Chiru-Anton A, Stanciu MM, Stoian AP, Jinga V, Nitipir C, Bucur A, Pituru TS, Arsene AL, Dragoi CM, et al: Clinical significance of serum melatonin in predicting the severity of oral squamous cell carcinoma. Oncol Lett 19: 1537-1543, 2020.

22. Olaru OT, Venables L, VAN DE Venter M, Nitulescu GM, Margina D, Spandidos DA and Tsatsakis AM: Anticancer potential of selected Fallopia Adans species. Oncol Lett 10: 1323-1332, 2015.

23. Pavlova NN, Hui S, Ghergurovich JM, Fan J, Intlekofer AM, White RM, Rabinowitz JD, Thompson CB and Zhang J: As Extracellular Glutamine Levels Decline, Asparagine Becomes an Essential Amino Acid. Cell Metab 27: 428-438.e5, 2018.

24. Bobrovnikova-Marjon EV, Marjon PL, Barbash O, Vander Jagt DL and Abcouwer SF: Expression of angiogenic factors vascular endothelial growth factor and interleukin-8/CXCL8 is highly responsive to ambient glutamine availability: Role of nuclear factor-kappaB and activating protein-1. Cancer Res 64: 4858-4869, 2004.
25. Ishak Gabra MB, Yang Y, Li H, Senapati P, Hanse EA, Lowman XH, Tran TQ, Zhang L, Doan LT, Xu X, et al: Dietary glutamine supplementation suppresses epigenetically-activated oncogenic pathways to inhibit melanoma tumour growth. Nat Commun 11: 3326, 2020.

26. Zhang J, Pavlova NN and Thompson CB: Cancer cell metabolism: The essential role of the nonessential amino acid, glutamine. EMBO J 36: 1302-1315, 2017.

27. García-de-Lorenzo A, Zarazaga A, García-Luna PP, Gonzalez-Huix F, López-Martínez J, Miján A, Quecedo L, Casimiro C, Usán L and del Llano J: Clinical evidence for enteral nutritional support with glutamine: A systematic review. Nutrition 19: 805-811, 2003.

28. Marur S and Forastiere AA: Head and Neck Squamous Cell Carcinoma: Update on Epidemiology, Diagnosis, and Treatment. Mayo Clin Proc 91: 386-396, 2016.

29. Bayman NA, Blackhall F, Jain P, Lee L, Thatcher $N$ and Faivre-Finn C: Management of unresectable stage III non-small-cell lung cancer with combined-modality therapy: A review of the current literature and recommendations for treatment. Clin Lung Cancer 9: 92-101, 2008.

30. Huang EY, Leung SW, Wang CJ, Chen HC, Sun LM, Fang FM, Yeh SA, Hsu HC and Hsiung CY: Oral glutamine to alleviate radiation-induced oral mucositis: A pilot randomized trial. Int J Radiat Oncol Biol Phys 46: 535-539, 2000.

31. Sarumathy S, Ismail AM and Palasimany A: Efficacy and safety of oral glutamine in radiation induced oral mucositis in patients with Head and Neck cancer. Asian J Pharm Clin Res 5: 138-140, 2012.

32. Zygogianni A, Kyrgias G, Kouvaris J, Pistevou-Gombaki K, Capezzali G, Zefkili S, Kokkakis J, Georgakopoulos J, Kelekis K and Kouloulias V: Impact of acute radiation induced toxicity of glutamine administration in several hypofractionated irradiation schedules for head and neck carcinoma. Head Neck Oncol 4: 86-92, 2012.

33. Chattopadhyay S, Saha A, Azam M, Mukherjee A and Sur PK: Role of oral glutamine in alleviation and prevention of radiation-induced oral mucositis: A prospective randomized study. South Asian J Cancer 3: 8-12, 2014.

34. Tsujimoto T, Yamamoto Y, Wasa M, Takenaka Y, Nakahara S, Takagi T, Tsugane M, Hayashi N, Maeda K, Inohara H, et al: L-glutamine decreases the severity of mucositis induced by chemoradiotherapy in patients with locally advanced head and neck cancer: A double-blind, randomized, placebo-controlled trial. Oncol Rep 33: 33-39, 2015.

35. Pattanayak L, Panda N, Dash MK, Mohanty S and Samantaray S: Management of Chemoradiation-Induced Mucositis in Head and Neck Cancers With Oral Glutamine. J Glob Oncol 2: 200-206, 2016.

36. Lopez-Vaquero D, Gutierrez-Bayard L, Rodriguez-Ruiz JA, Saldaña-Valderas $M$ and Infante-Cossio P: Double-blind randomized study of oral glutamine on the management of radio/chemotherapy-induced mucositis and dermatitis in head and neck cancer. Mol Clin Oncol 6: 931-936, 2017.

37. Pachón Ibáñez J, Pereira Cunill JL, Osorio Gómez GF, Irles Rocamora JA, Serrano Aguayo P, Quintana Ángel B, Fuentes Pradera J, Chaves Conde M, Ortiz Gordillo MJ and García Luna PP: Prevention of oral mucositis secondary to antineoplastic treatments in head and neck cancer by supplementation with oral glutamine. Nutr Hosp 35: 428-433, 2018.

38. Huang CJ, Huang MY, Fang PT, Chen F, Wang YT, Chen $\mathrm{CH}$, Yuan SS, Huang CM, Luo KH, Chuang HY, et al: Randomized double-blind, placebo-controlled trial evaluating oral glutamine on radiation-induced oral mucositis and dermatitis in head and neck cancer patients. Am J Clin Nutr 109: 606-614, 2019.

39. Pathak S, Soni TP, Sharma LM, Patni N and Gupta AK: A Randomized Controlled Trial to Evaluate the Role and Efficacy of Oral Glutamine in the Treatment of Chemo-radiotherapy-induced Oral Mucositis and Dysphagia in Patients with Oropharynx and Larynx Carcinoma. Cureus 11: e4855, 2019.

40. Algara M, Rodríguez N, Viñals P, Lacruz M, Foro P, Reig A, Quera J, Lozano J, Fernández-Velilla E, Membrive I, et al: Prevention of radiochemotherapy-induced esophagitis with glutamine: Results of a pilot study. Int J Radiat Oncol Biol Phys 69: 342-349, 2007.

41. Topkan E, Yavuz MN, Onal C and Yavuz AA: Prevention of acute radiation-induced esophagitis with glutamine in non-small cell lung cancer patients treated with radiotherapy: Evaluation of clinical and dosimetric parameters. Lung Cancer 63: 393-399, 2009. 
42. Topkan E, Parlak C, Topuk S and Pehlivan B: Influence of oral glutamine supplementation on survival outcomes of patients treated with concurrent chemoradiotherapy for locally advanced non-small cell lung cancer. BMC Cancer 12: 502-512, 2012.

43. Gul K, Muge A, Taner A and Sehri E: Oral glutamine supplementation reduces radiotherapy- induced esophagitis in lung cancer patients. Asian Pac J Cancer Prev 16: 53-58, 2015.

44. Chang SC, Lai YC, Hung JC and Chang CY: Oral glutamine supplements reduce concurrent chemoradiotherapy-induced esophagitis in patients with advanced non-small cell lung cancer. Medicine (Baltimore) 98: e14463, 2019.

45. Sayles C, Hickerson SC, Bhat RR, Hall J, Garey KW and Trivedi MV: Oral Glutamine in Preventing Treatment-Related Mucositis in Adult Patients With Cancer: A Systematic Review. Nutr Clin Pract 31: 171-179, 2016.
46. Leung HW and Chan AL: Glutamine in Alleviation of Radiation-Induced Severe Oral Mucositis: A Meta-Analysis. Nutr Cancer 68: 734-742, 2016.

47. Tang G, Huang W, Zhang L and Wei Z: Role of Glutamine in the Management of Oral Mucositis in Patients with Cancer: A Meta-Analysis of Randomized Controlled Trials. Nutr Cancer 19: $1-14,2021$.

48. Peng TR, Lin HH, Yang LJ and Wu TW: Correction to: Effectiveness of glutamine in the management of oral mucositis in cancer patients: a meta-analysis of randomized controlled trials. Support Care Cancer 29: 4893, 2021.

(c) (i) $\ominus$ This work is licensed under a Creative Commons cc) Attribution-NonCommercial-NoDerivatives 4.0 International (CC BY-NC-ND 4.0) License. 